\title{
Magnetismo da revolução no exilio português de José Celso Martinez Corrêa (1974-1976)
}

Magnetism of the revolution during the Portuguese exile of José Celso Martinez Corrêa (1974-1976)

\section{Paulo Bio Toledo}

Paulo Bio Toledo Doutorando do PPG em Artes Cênicas pela Escola de Comunicações e Artes da Universidade de São Paulo (ECA-USP)

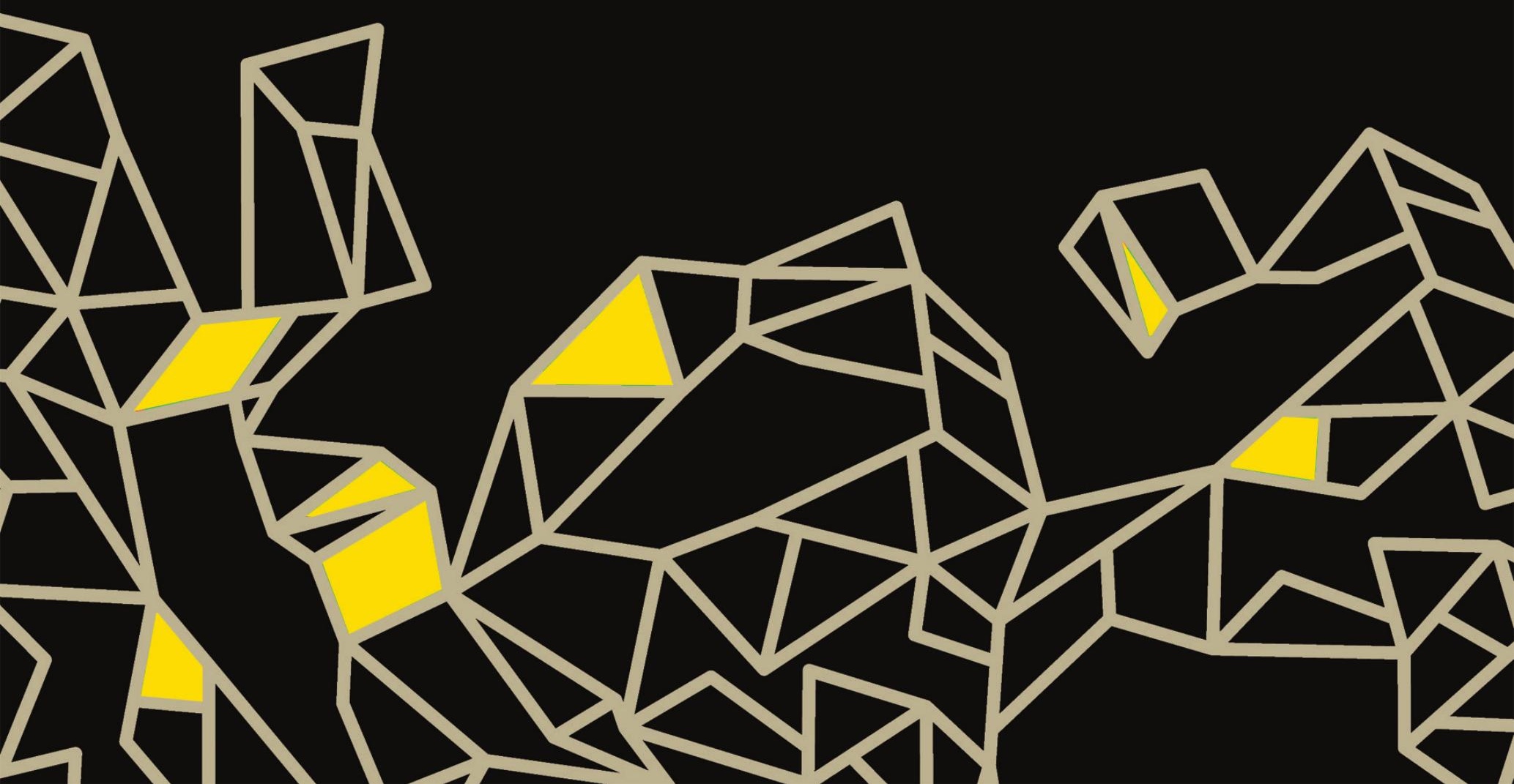




\section{Resumo}

O artigo debate o período de exílio que José Celso Martinez Corrêa e o Teatro Oficina viveram em Portugal durante a Revolução dos Cravos entre 1974 e 1976. A partir da reconstituição de um momento pouco documentado na trajetória do grupo, apresenta-se a hipótese de que o Oficina muda significativamente seus pressupostos estéticos e políticos quando em contato com o campo popular mais radical da revolução.

Palavras-chave: Zé Celso, Teatro Oficina, Revolução dos Cravos, Coro.

\section{Abstract}

This article discusses the period of exile that José Celso Martinez Corrêa and the Oficina Theater lived in Portugal, during the Carnation Revolution, between 1974 and 1976. From the reconstitution of a moment that is not well documented in the group's trajectory, it is hypothesized that the Oficina significantly changed its aesthetic and political presuppositions when in contact with the most radical popular field of the revolution.

Keywords: Zé Celso, Oficina Theater, Carnation Revolution, Choir.

José Celso Martinez Corrêa viveu momentos decisivos de sua trajetória artística durante seus anos de exílio entre 1974 e 1978. O diretor e diversos integrantes do Teatro Oficina passaram parte de seu exílio em Portugal logo após o golpe militar de 25 de abril de 1974, que colocou fim a 41 anos de ditadura fascista no país e ensejou momentos de insurreição popular e luta social jamais sequer imaginados.

Zé Celso chegou a Portugal dia 28 de setembro de 1974 no calor da revolução, depois de ser preso e torturado por quase um mês pela ditadura no Brasil. Ao deixar a prisão ele deixou também o país, seguido por todo o grupo numa espécie de autoexílio coletivo.

O Oficina chega então em um país às voltas com o que, segundo a historiadora portuguesa Raquel Varela (2014, p. 110), foi "a última Revolução do século XX a questionar a propriedade privada dos meios de produção". Assim que os capitães do Movimento das Forças Armadas (MFA) entraram em Lisboa, emitiram comunicados pelas rádios pedindo para que a população 
permanecesse em suas casas. Porém a primeira ordem do MFA ao tomar o poder do Estado foi ostensivamente ignorada. O povo saiu às ruas em massa e, desde aí, tornou-se o protagonista do processo revolucionário. "O golpe abriu as portas a uma situação social que ultrapassou imediatamente o MFA" (VARELA, 2014, p. 41) ${ }^{1}$.

Entre abril de 1974 e novembro de 1975, contabilizaram-se ondas de greve em todos os setores da economia, além de sucessivas ocupações de terras, fábricas e empresas que muitas vezes evoluíram para experiências de controle operário da produção (inclusive em rádios e jornais) (FERREIRA; LIMA; SANTOS, 1977, SUÁREZ, 2008). Foi um processo, enfim, que "fez tremer a estrutura da forma de acumulação capitalista" (VARELA, 2014, p. 159). De fato, os 19 meses da revolução proporcionaram talvez a mais maciça transferência de rendimentos do capital para o trabalhador no século XX: "no valor de uns impressionantes 18\%" (Ibid., p. 318).

A despeito do exílio soar muitas vezes como um tempo interrompido na trajetória criativa, Zé Celso e o Oficina participaram vivamente desse processo revolucionário e não saíram incólumes dele. Se, por um lado, os frutos deste vórtice parecem marcar até hoje a herança teatral da companhia, ao mesmo tempo remontam a uma conexão perdida e esquecida entre teatro e sociedade.

Quando o Teatro Oficina montou em 1968 a peça de Brecht $A$ vida de Galileu, deflagrou-se um choque entre os caminhos artísticos que se

1 Portugal era presidido desde 1968 por Marcelo Caetano, o sucessor de Antônio de Oliveira Salazar, que havia instituído uma ditadura de caráter fascista no país em 1933 e a liderado até se afastar por doença em 1968. O MFA foi uma organização clandestina fundada por capitães que serviam nas colônias. O movimento tinha ideias democráticas e reunia os militares insatisfeitos com a política das guerras coloniais. No dia 25 de abril, em um movimento coordenado de múltiplas guarnições e destacamentos, entram em Lisboa, chefiados pelo capitão Salgueiro Maia, e após um breve e emocionante impasse, que contou com a recusa de vários soldados de reprimir os capitães, depõem o presidente Marcelo Caetano, colocando fim ao período de 41 anos de ditadura no país. A senha para o início das operações foi a canção "Grândola, vila morena", de Zeca Afonso, executada na Rádio Renascença, ocupada por um destacamento de capitães. Em seus versos, escuta-se: "Dentro de ti, ó cidade/ O povo é quem mais ordena/ Terra da fraternidade/ Grândola, vila morena", versos que antecipam o período de revolução popular que se segue ao fim da ditadura. 
apresentavam naquele momento. A décima cena da peça - quando o "ensinamento de Galileu se difunde entre o povo" numa terça-feira de carnaval em 1632 (BRECHT, 1977, p. 165) - era interpretada por um grupo de jovens atores recrutados do coro que montara Roda viva, sob direção de Zé Celso naquele mesmo ano. Apesar da forte resistência dos antigos atores profissionais que integravam o elenco, aqueles jovens irreverentes despertavam grande simpatia em Zé Celso e viam a si mesmos como o Coro do Oficina.

A cena do carnaval era uma ruptura durante a representação. Os jovens atores propunham uma vivência sensorial com a plateia e frequentemente entravam em cena após utilizar substâncias alucinógenas. Era um momento que às vezes se estendia por longo tempo e se descolava totalmente do restante do espetáculo - "com o coro rompendo drasticamente o fio lógico da peça para realizar os apelos sensoriais de sua pulsão performativa" (PECORELLI, 2014, p. 42). A primeira montagem de Galileu Galilei ficou marcada por essa incongruência interna. Mais que isso, inaugurou "uma crise no interior do grupo" (SILVA, A. S., 1977, p. 64) que se estenderia por vários anos até 1973. Nessa luta, Zé Celso cada vez mais se colocava ao lado do coro, fortalecendo sua posição. Montagens seguintes como Na selva das cidades (1969) e Gracias, señor (1972), bem como a viagem pelo país empreendida pelo grupo em 1971 e a ideia de "te-ato" como superação do teatro representacional burguês apontam fortemente para o caminho aberto pelo coro.

Quando Zé Celso chega em Lisboa seguido por 15 integrantes do que já era a Comunidade Oficina Samba², as primeiras intervenções artísticas do grupo naquele turbilhão revolucionário foram criações pensadas justamente a partir da polêmica cena do Carnaval em Galileu. A principal peça de intervenção criada pelo grupo ganhou o nome de Ensaio geral do carnaval do povo. Era uma ação teatral apresentada em fábricas, festas populares, bairros operários e terras ocupadas. A proposta da ação era que o público popular fosse se integrando ao coro do Oficina em um grande momento de carnaval coletivo.

Em março de 1975, a Comunidade Oficina Samba foi assunto de duas longas reportagens a partir de entrevistas realizadas pelo jornal O Século, um tradicional periódico português fundado em 1880 que tivera toda a antiga

2 Samba era uma sigla para Sociedade Amigos Brasil Animações. A Comunidade Oficina Samba foi o novo nome do Teatro Oficina a partir de 1973. 
administração expulsa por seus trabalhadores logo após o 25 de abril de 1974. $\mathrm{Na}$ primeira das reportagens, publicada dia 5 de março, a posição do grupo foi elaborada coletivamente, refletindo uma forte atitude em torno da ideia de comunidade $^{3}$. Mas o que logo chama a atenção é o radicalismo das posições políticas que o grupo assume naquele momento da revolução.

Às vésperas da primeira eleição legislativa após o fim do fascismo, a Comunidade Oficina Samba se posiciona contra a farsa da democracia burguesa, vista como "despressurização" e "contensão" do processo revolucionário (RODRIGUES, U. T., 1975). Afirma-se "a favor do movimento que vem de baixo para cima" (Ibid.), ao mesmo tempo que revela seu alinhamento com um grupo de extrema-esquerda de tendência maoísta no cenário revolucionário Português: "há um marco de mudança do teatro político português. É o congresso da L.U.A.R. [Liga de Unidade e Ação Revolucionária]" (Ibid.).

$O$ referido congresso aconteceu entre os dias 22 e 24 de fevereiro de 1975. A LUAR, que surgira em 1967 como grupo de resistência à ditadura, recusava a política partidária, defendia uma ação de base com trabalhadores, camponeses, estudantes e soldados do país e tinha por lema a ideia de "poder popular". Suas posições ultrapassavam a retórica política e, no espírito do maio francês de 1968, buscavam projetar também novas possibilidades de vida social e cultural. Não por acaso, contava com a simpatia de muitos artistas como, por exemplo, o músico Zeca Afonso, autor de "Grândola, Vila Morena," canção que foi a senha para os capitães do MFA iniciarem a tomada do poder no 25 de abril. Uma das principais posições da LUAR é exposta em reportagem da Revista Flama sobre o congresso: a revolução socialista deveria ir além da socialização dos meios de produção e "alargar-se a toda a sociedade, transformando-a radicalmente e transformando-se ela própria numa verdadeira revolução cultural" (LOURO, 1975, p. 51) 4 .

3 Logo ao chegar no país, habitam juntos um antigo casarão em Lisboa que era usado antes do 25 de abril como centro de inteligência e tortura da temida PIDE/DGS (Polícia Internacional e de Defesa do Estado, que em 1969 passa a ser Direção-Geral de Segurança). Ali, junto a exilados de inúmeros outros países, eles vivem uma espécie de laboratório social regado ao uso de substâncias alucinógenas e alimentação macrobiótica.

4 Apesar do rótulo de extremismo que agrupamentos como a LUAR recebiam, naquele momento não foram coletivos insignificantes ou folclóricos de posições ortodoxas. Segundo o historiador Fernando Rosas (2014, p. 12): "a extrema-esquerda, mesmo pulverizada e em guerra interna, teve a força social e política suficiente para impedir a hegemonia político-ideológica do PCP [Partido Comunista Português] no processo". 
A comunidade do Oficina via na LUAR "uma ruptura com a postura política careta", e afirmava que "o programa de teatro da L.U.A.R. é sair das quatro paredes e invadir o cotidiano" (RODRIGUES, U. T., 1975). Não uma ideia abstrata de cotidiano, mas a realidade concreta que vivia em convulsão social desde o início da revolução. Por meio da organização de esquerda, o Oficina estabeleceu contato com trabalhadores em luta pelo país e se aproximou de experiências radicais da revolução portuguesa. Atuou diretamente, por exemplo, na enorme ocupação de terra na Herdade Torre Bela, região do Ribatejo, organizada por uma cooperativa agrícola de lavradores ${ }^{5}$; ou ainda com os grupos radicais de soldados que pouco depois desafiariam os capitães de abril e formariam os Soldados Unidos Vencerão (SUV) - "iam nos buscar de tanque pra gente fazer nosso trabalho nos quartéis" (CORRÊA, 2006, p. 24). Assim, no início de 1975, atuando nesses ambientes de luta de classes escancarada, o Oficina realiza ações que aproximavam intimamente sua atividade teatral da luta popular. Em entrevista de 2006, Zé Celso relembra: "o povo tomou conta de divisão, dos jornais, das fábricas! A gente participava de tudo isso [...]. As fábricas eram dos operários... A gente criava espetáculo com eles” (Ibid., p. 23).

A posição radical do Oficina deflagrou também um processo de constante tensão entre o grupo e as forças hegemônicas na política pós-25 de abril, como o Partido Socialista, o Partido Comunista Português e o MFA. Após apresentações para camponeses em São João do Campo, o grupo é convocado a prestar esclarecimentos e, em seguida, perde os subsídios que recebia do Estado. Decerto pesou na decisão seu alinhamento a organizações de extrema-esquerda, como a LUAR, que tinha se descolado dos impasses políticos e burocráticos da revolução e se associado à luta popular de base e aos exercícios de democracia direta. Eram grupos frequentemente acusados de radicalismo pequeno-burguês, que atrapalhavam as tarefas pragmáticas de fazer funcionar o país após a derrubada do fascismo.

Apesar do impasse vivido em meio ao turbilhão revolucionário português e do corte de subsídios e apoio estatal, a Comunidade Oficina Samba seguiu trabalhando em torno da ideia de poder popular e de uma vida social mais livre, organizada de baixo para cima. A ideia de coro passou a ser central

5 Sobre a ocupação ver o documentário Torre bela. Direção: Thomas Harlan. Portugal, Itália, RFA: Cooperativa Era Nova, Societá Cinematográfica Italiana (SCI), Albatroz, 1977. 
e constitutiva para todo o trabalho teatral do grupo em Portugal. Além da intervenção Ensaio geral do carnaval do povo, também o espetáculo Galileu foi inteiramente remontado a partir da cena em coro do carnaval. O que era um momento dissonante no espetáculo original passou a ser o motor da remontagem.

Valendo-se de fatos como esse, Luiz Fernando Ramos (2005) em excelente ensaio sobre o assunto defende que os anos de exílio do Oficina teriam, então, dado continuidade decisiva ao caminho apontado pelo grupo desde 1968 (e radicalizado nos primeiros anos da década de 1970). Para o autor, a viagem do Oficina pelo Brasil em 1971 e o espetáculo Gracias, senõr são "o início de uma fase que tem o seu ápice na revolução portuguesa" (2005, p. 274). Trata-se, para o crítico, de uma fase na qual o coro é pensado como elemento fundante da prática teatral. Esse seria um dos alicerces do grupo desde então: "mesmo com o esgotamento daquela fase, Zé Celso nunca mais deixou de priorizar o trabalho com o coro" (Ibid., p. 277).

Os anos em Portugal teriam sido, portanto, o momento de organização do princípio coral que estaria presente em todo o desenvolvimento subsequente na história do Teatro Oficina até a atualidade. Com efeito, aquele parece mesmo ter sido um período decisivo na trajetória artística do grupo, marcando de forma indelével seu teatro.

Porém, desde o início dos trabalhos em Portugal, o próprio grupo sustenta uma diferença significativa com relação ao trabalho que vinha realizando no Brasil desde 1968. Na referida reportagem do jornal O Século, a Comunidade Oficina Samba afirmava que "os movimentos todos de 68 ocorreram isoladamente: a revolução cultural, a revolução política, aconteceram no Brasil dentro de uma faixa isolada" (RODRIGUES, U. T., 1975). Para eles, as experiências do teatro contracultural no Brasil da década de 1970 padeciam do "mesmo problema de Galileu: a falta de aliança com o povo" (Ibid.). O coro aqui era outro.

Chama logo a atenção a escolha do grupo em trabalhar com Galileu e não com Na selva das cidades ou Gracias, señor. No início da década de 1970, Zé Celso via muito mais interesse na "fase anárquica" do primeiro Brecht que a montagem de Na selva das cidades buscava sublinhar. Em 1969 ele diz: "Eu fico com o touro selvagem que o jovem Brecht soltou, mas que depois 
ele mesmo [...] teve que amansar, estruturalizar e institucionalizar" (CORRÊA, 1998, p. 142). Para o diretor: "Galileu foi ficando a velha resistência pacifista e coexistente da Segunda Guerra Mundial, a conquista da Lua, o bom-mocismo racionalista e portanto a esposa velha que acaba por chatear" (Ibid., p. 141). E em 1972, às voltas com o espetáculo Gracias, señor, Zé Celso afirma sobre Galileu: "foi muito interessante para a época, mas sem a menor importância do ponto de vista teatral. Galileu denunciava uma coisa e conversava 'sobre' ela" (Ibid., p. 168). E confessa: "Em Galileu nós recuamos totalmente. Na época, eu achava uma merda fazer aquilo" (Ibid.). No entanto, assim que o Oficina chega a Portugal em 1974, naquele ambiente em revolução, ou seja, muito mais afeito às transformações sociais imaginadas pelo grupo, é Galileu, e somente Galileu, que vai perpassar quase todas as suas ações teatrais.

No contexto de sua primeira montagem em 1968, Zé Celso vê na peça de Brecht o argumento de que "uma revolução cultural sozinha não resolve absolutamente nada" (RODRIGUES, T. C., 1968, p. 11). Não deixa de ser significativa a escolha do grupo pela retomada desse texto em Portugal, escolha marcada ainda pela disposição crítica de "acentuar na peça o aspecto de luta de classes" (RODRIGUES, U. T., 1975). Esse tipo de escolha nos anos de exílio parece indicar um corte na trajetória do grupo.

Em 1971, no momento em que o Oficina busca romper com a ideia de teatro no Brasil, ele nega também os vestígios de materialismo presente em suas origens. Desde 1969, Zé Celso manifesta desconforto com, por exemplo, o símbolo do grupo (a bigorna) que faria parte "de uma visão de mundo de dez anos atrás, onde a visão trabalhista e operária era moralmente mais correta" (CORRÊA, 1998, p. 147). Em 1971, a bigorna como símbolo é rejeitada e substituída por uma foto da ação teatral que realizaram com milhares de estudantes na UnB naquele ano (Ibid., p. 192). Em depoimento de 1973, Zé Celso refere-se a esse imaginário operário como algo perdido no passado e afirma com ironia: "na época tinha uma bigorna como símbolo, indicava trabalho de equipe, trabalho braçal, quase uma fábrica" (Ibid., p. 17). Já em 1975 em Portugal, nos créditos do filme O Parto, montado por Zé Celso e Celso Luccas, mas assinado por toda a Comunidade Oficina Samba como obra coletiva, a bigorna voltou a figurar com destaque como símbolo do grupo (SILVA, I. O. P., 2006, p. 62). 
A associação produtiva entre arte e a ideia de trabalho ganhou um novo sentido naquele momento de conexão viva com os trabalhadores em meio à revolução portuguesa. Em outra entrevista para o jornal O Século em 1975, o grupo reafirma e sublinha o imaginário negado anos antes: "o Oficina nasceu em função da desmistificação de um conceito de trabalho de teatro [...] para eleitos superinspirados gênios. Para provar que o trabalho de teatro é [...] árduo, trabalho operário, de oficina" (DINAMITAÇÃO, 1975).

O Parto é um documentário sobre a revolução montado a partir de material do arquivo da Rádio e Televisão de Portugal (RTP), principal emissora do país que foi nacionalizada após o 25 de abril. Foi uma experiência de montagem abertamente inspirada na vanguarda cinematográfica soviética, como Dziga Vertov e Serguei Eisenstein (SILVA, I. O. P., 2006, p. 55). A partir da filmagem de um parto ocorrido no dia 25 de janeiro de 1975, há exatos nove meses do 25 de abril de 1974, o filme busca construir uma narrativa sobre a revolução em processo. Apresenta então imagens de Portugal sob regime salazarista e da guerra colonial secundadas pela festa da revolução. Em trabalho sobre o cinema do Oficina, a pesquisadora Isabela Oliveira P. da Silva (2006, p. 62) percebe que o parto que dá nome ao filme "é, em termos simbólicos, um parto duplo." Numa das cenas finais, um plano com o montador é intercalado à imagem do médico realizando o procedimento: "o corte na película cinematográfica é feito simultaneamente ao corte do cordão umbilical" (Ibid.). De modo que "o nascimento da criança simboliza a revolução e o nascimento do próprio filme" (Ibid.). O corte do cordão é um corte na vida social e na ideia de arte, apresentadas como partes de um mesmo movimento histórico.

O filme termina com o letreiro: "A Revolução é uma CRIAÇÃO COLECTIVA de um Trabalho novo, diário, para a transformação de toda a vida". O termo "Trabalho novo" logo remete ao trabalho realizado pelo grupo em 1971 no Brasil, mas ao mesmo tempo ganha nova acepção. Nos anos de exílio, "Trabalho novo" está associado ao processo de um mundo em transformação. A construção momentânea de um novo mundo demandaria uma nova ideia de arte. No filme Vinte e cinco, realizado em Moçambique entre 1975 e 1976 por Zé Celso e Celso Luccas com apoio da RTP e da Frente de Libertação de Moçambique (Frelimo), um dos planos mostra uma criança africana aprendendo a operar uma câmera. A singela sequência, que contém em si as ideias 
de revolução e de independência, projeta também uma nova relação produtiva em arte, que, no limite, recusa a ideia de autonomia burguesa da atividade. Em um tempo revolucionário todos seriam artistas. Esse parece ser o ideal do conceito de "Trabalho novo" para Zé Celso e o Oficina durante esses anos.

O impulso vanguardista de "reconduzir a arte à práxis vital" (BÜRGER, 2008, p. 58) brilha no trabalho do grupo desde 1968. Mas a partir do exílio esse impulso mudou de sentido ao associar-se a uma posição radical na luta de classes. Toda a mística de fundamento mágico-religioso que gravitava em torno das ações do grupo em 1971 é suplantada por uma prática fortemente ligada à luta dos trabalhadores, camponeses e soldados em meio à revolução portuguesa.

Em 1972, falando sobre a experiência de viagem do Oficina pelo sertão pernambucano na cidade de Mandassaia, Zé Celso disse a respeito do encontro com a população pobre: "nós encontramos alguns pontos de contato através do terreno místico, do humano mais profundo; afora isso, tudo nos separava" (CORRÊA, 1998, p. 190). Em 1974, pouco antes de deixar o Brasil, Zé Celso via o teatro como algo "profético e messiânico", "Prometeu" detentor do fogo divino (Ibid., p. 284). O teatro seria como um "segredo de amor revelado para todos os homens e nesse segredo está o segredo da mudança da vida" (Ibid., p. 286, grifo nosso). Mas em 1975, imbuída pelo espírito de Galileu, a Comunidade Oficina afirma: "Os segredos das ciências e das artes descobertos por pequenos burgueses [...] somente terão eficácia quando forem usados pelo povo" (DINAMITAÇÃO, 1975, grifo nosso).

Quando Zé Celso retorna ao Brasil no final de 1978 é a esse sentido altamente politizado do coro que ele busca dar prosseguimento com o Oficina. Um coro que se quer sempre maior, que busca romper com a ideia de especialização na arte. Em plena ditadura, no 1ํ de maio de 1979 o grupo apresenta Ensaio para um carnaval do povo na Praça da Sé, no contexto das grandes greves de trabalhadores do ABC. O espetáculo terminava com a faixa "Criar, criar, poder popular,' palavra de ordem do período ligada a posições da esquerda radical e bastante proclamada pela LUAR. E em entrevista para o jornal Folha de S.Paulo, Zé Celso afirma ser preciso lutar "lado à lado com as reivindicações dos trabalhadores, porque também pertencemos a essa classe" (NATALE, 1979, p. 12). 
De fato, como já sugere Luiz Fernando Ramos (2005), a experiência do exílio em tempos revolucionários parece ter sido decisiva para todo o trabalho subsequente do grupo. No entanto, distante de um momento de intensidade revolucionária, a formatação coral do trabalho em busca da conexão produtiva com os trabalhadores em luta vai perdendo espaço. A terminologia de engajamento dá lugar a uma reposição gradual da mistificação. E com isso, pouco a pouco, a pulsão criativa do grupo se estabiliza em forma cultural.

A produção contemporânea do Oficina seria assunto para outro debate. Afinal, é repleta de ambivalências e idas e vindas. Contudo, de modo geral, chama a atenção que a nova mudança de sentido a partir da década de 1980 foi também defendida como uma espécie de triunfo do projeto vanguardista iniciado em 1968. A inflexão dos tempos revolucionários em Portugal é vista, desde então, como apenas mais um capítulo desse bem-sucedido processo que culmina no Teat(r)o Oficina Uzyna Uzona e na coroação de Zé Celso como espécie de guru prometeico, ou cacique dionisíaco.

Em filme recente sobre sua vida, Zé Celso conta sobre uma significativa mudança de divindade pela qual passou:

Eu, durante muito tempo eu fui um chato, eu fui um Prometeu. Eu ficava brigando. Eu era oprimido. Ficava reclamando, [...] Até que na passagem do ano, já depois da volta do exílio, me veio às mãos Dioniso. E eu percebi que não estava com nada ficar ali reclamando. Bom, meu deus é Dioniso, eu quero um deus que te ofereça vinho, que te faça dançar, tomar banho de cachoeira... Aí minha vida mudou radicalmente, o Teatro Oficina mudou radicalmente ${ }^{6}$.

Em entrevista realizada em 2012, diz ainda:

Eu quis fazer Prometeu acorrentado. Mas logo depois [...] o mito mudou pra mim inteiramente. Eu reneguei Prometeu e assumi Dioniso [...] essa relação de oprimido e opressor, de teatro do oprimido, eu despacho. Eu despachei com Prometeu e encontrei Dioniso. (CORRÊA, 2012, p. 9)

A confissão de Zé Celso revela a vontade de seguir trabalhando com formas corais e coletivas do teatro, mas sem lidar com o potencial de luta política

6 Transcrito do filme Evoé: retrato de um antropófago. Dir. Tadeu Jungle e Elaine César. Prod. Paulo Roberto Schmidt. São Paulo: Iconoclássicos, 2011. 
que tais recursos possuem. Ou seja, manter algo do trabalho realizado em Portugal, mas livre do engajamento - "essa relação de oprimido e opressor" que o organizava. Neste momento, a ritualização suplanta a encontro coletivo; a metafísica existencial novamente toma o espaço da luta de classes.

Apesar disso, a proposição vanguardista de integração entre arte e vida se mantém como fundamento do trabalho do Oficina e talvez seja a mais reluzente marca de sua prática artística. Mas como afirma Peter Bürger (2008, p. 113) em sua reflexão sobre as primeiras vanguardas históricas do início do século XX: "na sociedade do capitalismo tardio, intenções dos movimentos históricos de vanguarda são realizadas com sinais invertidos":

Os meios com os quais os vanguardistas esperavam produzir a superação da arte tinham adquirido o status de obra de arte [...] a neovanguarda institucionaliza a vanguarda como arte e nega, com isso, as genuínas intenções vanguardistas. (lbid., p. 123)

A forma, que um dia teve consequências e reverberações revolucionárias, vira mais um produto no velho escaninho da cultura e mal resiste à formatação como mercadoria, embora creia que ainda tem poder de tensão. Isso na mesma medida em que esfumaça o momento de verdade que o projeto um dia teve.

\section{Referências bibliográficas}

BRECHT, B. A vida de Galileu. Tradução Roberto Schwarz. São Paulo: Abril cultural, 1977.

BÜRGER, P. Teoria da vanguarda. Tradução José Pedro Antunes. São Paulo: Cosac \& Naify, 2008.

CORRÊA, J. C. M. O tempo rodou num instante: depoimento. Entrevista concedida a Nina Hotimsky. Traulito, São Paulo, n. 5, p. 5-9, abr. 2012.

Revolição: lição de voltar a querer. Camarim, São Paulo, ano 9, n. 38, p. 20-28, 2006.

Primeiro ato: cadernos, depoimentos, entrevistas (1958-1974). Seleção, organização e notas por Ana Helena Camargo de Staal. São Paulo: Editora 34, 1998.

DINAMITAÇÃO cultural. O Século, Lisboa, 29 mar. 1975

FERREIRA, V. M.; LIMA, M. P.; SANTOS, M. L. O 25 de abril e as lutas sociais nas empresas. Porto: Afrontamento, 1977. 3 v. 
LOURO, R. Congresso da LUAR: criar o poder popular. Revista Flama, Lisboa, n. 1.409, p. 48-53, mar. 1975.

NATALE, D. Ensaio para um carnaval do povo. Folha de S. Paulo, São Paulo, 6 maio 1979. Folhetim, p. 12.

PECORELLI, B. A pulsão performativa de Jaceguai: aproximações e distanciamentos entre o campo artístico da performance e a prática cênica do Teat(r)o Oficina nos espetáculos Macumba antropófoga e Acordes. 2014. 192 f. Dissertação (Mestrado em Teoria e Prática do Teatro) - Escola de Comunicação e Artes, Universidade de São Paulo, São Paulo, 2014.

SUÁREZ, M. A. P. Contra a exploração capitalista: comissões de trabalhadores e luta operária na Revolução Portuguesa (1974-1975). 2008. Dissertação (Mestrado em História dos Séculos XIX e XX) - Faculdade de Ciências Sociais e Humanas, Universidade Nova de Lisboa, Lisboa, 2008.

PORTO, C. Brecht com samba dentro. Diário de Lisboa, Lisboa, 14 abr. 1975.

RAMOS, L. F. Dez anos de Usina Uzona e trinta anos do exílio português. In: MARGATO, I.; GOMES, R. C. (Orgs.). Literatura/Política/Cultura (1994-2004). Belo Horizonte: UFMG, 2005.

RODRIGUES, T. C. Galileu, este velho subversivo. Folha da tarde, São Paulo, 4 dez. 1968, p. 11.

RODRIGUES, U. T. Comunidade Oficina Samba - fins e meios, teatro e revolução. O Século, Lisboa, 5 mar. 1975.

ROSAS, F. Ser e não ser: notas sobre a Revolução Portuguesa de 74/75 no seu 40. Aniversário. Revista Vírus, n. 5, p. 4-12, abr. 2014.

SILVA, A. S. Oficina: do teatro ao te-ato. São Paulo: Perspectiva, 1977.

SILVA, I. O. P. "Bárbaros tecnizados": cinema no Teatro Oficina. 2006. 175 f. Dissertação (Mestrado em Antropologia Social) - Faculdade de Filosofia, Letras e Ciências Humanas, Universidade de São Paulo, São Paulo, 2006.

VARELA, R. História do povo na revolução portuguesa. Lisboa: Bertrand, 2014.

Recebido em 24/09/2017

Aprovado em 1\%05/2018

Publicado em 29/06/2018 